Please do not remove this page

RMIT

UNIVERSITY

\title{
Saying what you think: an analysis of French and Australian English non-native speaker expression of subjectivity.
}

Mullan, Kerry Jane

https://researchrepository.rmit.edu.au/esploro/outputs/9921858522201341/filesAndLinks?institution=61RMIT_INST\&index=null

Mullan, K. J. (2012). Saying what you think: an analysis of French and Australian English non-native speaker expression of subjectivity. In Subjectivity in Language and in Discourse (pp. 193-227). Emerald Group Publishing Ltd.

https://researchrepository.rmit.edu.au/discovery/fulldisplay/alma9921858522201341/61RMIT_INST:Resea rchRepository

Repository homepage: https://researchrepository.rmit.edu.au

(C) 2012 Emerald Group Publishing

Downloaded On 2023/04/26 15:25:38 +1000 
Thank you for downloading this document from the RMIT Research Repository.

The RMIT Research Repository is an open access database showcasing the research outputs of RMIT University researchers.

RMIT Research Repository: http://researchbank.rmit.edu.au/

\section{Citation:}

Mullan, K 2012, 'Saying what you think: an analysis of French and Australian English non-native speaker expression of subjectivity.' in Nicole Baumgarten, Inke Du Bois and Juliane House (ed.) Subjectivity in Language and in Discourse, Emerald Group Publishing Ltd, United Kingdom, pp. 193-227.

See this record in the RMIT Research Repository at:

http://researchbank.rmit.edu.au/view/rmit:20323

Version: Submitted Version

Copyright Statement: ㄷ 2012 Emerald Group Publishing

Link to Published Version:

http://researchbank.rmit.edu.au/view/rmit:20323

\section{PLEASE DO NOT REMOVE THIS PAGE}




\section{Saying what you think: an analysis of French and Australian English non-native speaker expression of subjectivity}

Kerry Mullan

\section{Introduction}

This chapter examines the expression of subjectivity in a second language (hereafter L2) by non-native French and Australian English speakers through the specific epistemic expressions I think, je pense (literally 'I think'), je crois (literally 'I believe'), and je trouve (literally 'I find') ${ }^{1}$. These expressions will hereafter be referred to as comment clauses, since they can be considered epistemic parentheticals which are clausal in origin and which function as pragmatic markers Brinton (2008). As Biber, Johansson, Leech, Conrad, \& Finegan.. point out, comment clauses are also usually short, loosely connected to the main clause, and can appear in a variety of positions (1999, p. 197); all of these features apply to I think and its equivalents in this study.

Early on in their studies of French and English as a second (or foreign) language, learners are usually presented with je pense, je crois and je trouve as having the literal meanings of I think, I believe and I find; while this is true in some cases, it does not present a complete picture. These comment clauses are usually introduced to the learner again later as ways of prefacing an opinion (with little explanation beyond that). This limited presentation to L2 learners is overly simplistic and eventually quite unhelpful, since in fact, as we shall see, the equivalent of the French comment clauses is usually I think in native English speaker interaction, where $I$ believe and $I$ find are used far less frequently.

Numerous studies have been carried out on such comment clauses in interaction, and the importance of pragmatic competence in one's second language is also well documented in the literature (Kasper \& Rose, 2002; Tateyama, Kasper, Mui, Tay, \& Thananart, 1997; Thomas, 1983 inter alia), and yet, as Müller (2005, p. 14) also points out, there are very few interlanguage pragmatics studies which combine these elements by investigating the acquisition of such comment clauses by L2 learners. ${ }^{2}$

The present study attempts to address this situation by combining a semantic and interactional analysis of these four comment clauses, to illustrate their non-isomorphic nature. ${ }^{3}$ I will argue that the underlying inherent semantic content of each comment clause is distinct, and that disclaiming knowledge of the upcoming proposition is integral to I think

\footnotetext{
${ }^{1}$ Unless stated otherwise, all references to je pense, je crois, and je trouve also refer to the inclusion of the subordinator que ('that') where this is syntactically obligatory at the beginning of a proposition in standard European French, i.e. je pense que, je crois que, and je trouve que (unless where this latter is followed by a noun phrase).

2 Müller refers specifically to discourse markers.

${ }^{3}$ Cf. also Doro-Mégy (2008) for a contrastive study of think, believe, croire and penser with a particular focus on the constraints of translating these predicates in literature.
} 
in Australian English, while this need to distinguish fact from opinion is not part of the core meaning of any of the three French comment clauses.

An earlier study of the discourse of native speakers (NS) of French and Australian English (Mullan, 2007, 2010) found that interactionally all four comment clauses are multifunctional and have three main roles in discourse as follows: organisational (e.g. to mark a boundary in discourse), semantic (to express an opinion/level of certainty) and pragmatic (as a face saving device).

Using examples from authentic non-native speaker discourse, this chapter will discuss how these semantic and interactional nuances are not always evident to non-native speakers (NNS) in their second language, and what effect this can have in interaction when they use these expressions of subjectivity in their L2. Using Müller's (2005) comprehensive study of four discourse markers as used by non-native and native (American) English speakers as an example, I set out to answer the following specific questions in relation to my own data (adapted from Müller, 2005, p. 24):

a) How does the frequency of the comment clauses in the (French and English) non-native speaker discourse compare with the frequency in the native speaker discourse

b) Which functions do the comment clauses have in the native speaker discourse?

c) Which of these functions also occur in the non-native discourse?

d) How do the frequencies of the functions of the comment clauses compare in native and non-native speaker discourse?

\section{Data}

The analysis is based on a corpus of six conversations totalling four hours, and is part of a larger project which originally involved the interactional and semantic analysis of NS use of the comment clauses $I$ think, je pense, je crois and je trouve (Mullan, 2007, 2010). The participants are aged between 22 and 42, of middle-class background, all have (or are studying for) a university degree, are all of European origin and come from different parts of Australia and France. The participants were made up of two complete strangers meeting for the first time, and are all speakers of standard French or general Australian English. ${ }^{4}$

It is generally accepted that length of residency in a foreign country and native speaker contact (Müller, 2005, p. 50) can affect one's interactional style in the target language (and indeed the first language (L1)). For this reason, the participants were chosen for this study on the basis that they had all spent less than two years in a country where their L2 was spoken.

\footnotetext{
4 It is generally agreed that there are three main types of Australian English: broad, general and cultivated, and that these are largely distinguished on the basis of vowel pronunciation (cf. Horvath, 1985). Hansen (1997, p.154) defines standard French as "the kind which is spoken by educated Parisian speakers and which exhibits no noticeable regional or social characteristics”. While this may seem a narrow definition, it is representative of the French spoken by the participants.
} 
Another important factor to be considered in any study of this nature is of course L2 proficiency. Although the speakers were not asked to undergo a proficiency test, it was made clear at the time of recruiting the participants that they would be require a reasonable level of fluency, since they would be asked to hold a conversation in their L2 for approximately 45 minutes. Whilst the proficiency levels of the speakers varied somewhat, none of them had any trouble holding a conversation, and all displayed a reasonable use of colloquial expressions and a wide range of vocabulary. However, as will be seen, the proficiency levels did affect some non-native speakers' intonation in their L2, which in turn affected the prosody of the comment clauses under investigation, as uttered by the NNS. More information concerning the participants' prior studies in the target language might therefore have been useful, as a measure of control.

While the study did not control for age, gender, socio-economic background or town of origin of the participants, where possible, the speakers' backgrounds and their relationship to each other were as similar as possible, to enable the findings to be more comparable. An attempt was made to ensure that the conversations were also similar in terms of set-up, length and topics discussed. These included life in Australia and/or France, the role of honesty in a relationship, and the importance of expressing one's opinion. The topics were chosen on the basis that the participants would have knowledge and perhaps personal experience of these issues, and would therefore be likely to elicit an opinion from the participants.

It must of course be acknowledged that the following analysis is only directly representative of the present small set of data; however, the findings have been reached as part of the analysis of a larger corpus of French and Australian English NS (Mullan 2007, 2010), and are therefore somewhat more widely generalisable. Tables 1 and 2 provide details of the participants in the present study (pseudonyms are used throughout).

Table 1 Participants of French conversations

\begin{tabular}{ll}
\hline Native speaker & Non-native speaker \\
\hline Christine (f) & Jane (f) \\
Carine (f) & Darren (m) \\
Louis (m) & Karen (f) \\
\hline
\end{tabular}

Table 2 Participants of Australian English conversations

\begin{tabular}{ll}
\hline Native speaker & Non-native speaker \\
\hline Beth (f) & Daniel (m) \\
Heather (f) & Marie (f) \\
Len (m) & Suzanne (f) \\
\hline
\end{tabular}

The participants were paired with a member of the opposite sex in each conversation, except for one all-female dyad in each group. For reasons of participant availability at the time of data collection, there was no corresponding all-male dyad in each group, which prevented me from controlling for gender in this study. However, while one might expect 
certain gender differences to appear, the analysis showed that this was not in fact the case. Some of Coates' earlier research $(1997,1998)$ has indicated that the topic of conversation and the degree of solidarity between speakers can affect the function of epistemic modals in conversation, and can thus lead to differences in usage by gender. However, given that the topics discussed by my participants were generally chosen for them, and that these topics and the degree of solidarity were similar across all the dyads, my study remains unaffected by these findings.

The participants were recorded in conversation with each other; although I was also present as the researcher, my participation was limited to asking questions on certain topics to initiate the conversation between the two speakers, and to adding comments occasionally. Despite the fact that the conversations recorded for this corpus were pre-arranged and therefore not impromptu, the data conform to Levinson's definition (1983) of conversation as

[...] that familiar predominant kind of talk in which two or more participants freely alternate in speaking, which generally occurs outside specific institutional settings like religious services, law courses, classrooms and the like. (p. 284)

The conversations are authentic and consist of natural data in response to certain questions for the purpose of the data collection. Recording them in a controlled setting ensured a certain consistency of topics. Since the focus of the research was to examine the different ways of expressing opinions in French and Australian English, it was necessary to provide topics to the participants which would result in a discussion where opinions were exchanged. This then allowed for a direct comparison of the data.

The number of minutes, words and intonation units per speaker are provided in Tables 3 and 4.

Table 3 Words and intonation units by NS and NNS French speakers

\begin{tabular}{lllll}
\hline Participants & Minutes & Words & $\begin{array}{l}\text { Intonation } \\
\text { units }\end{array}$ & $\begin{array}{l}\text { Intonation units } \\
\text { per 100 words }\end{array}$ \\
\hline Christine & \multirow{2}{*}{37.29} & 3538 & 566 & 16 \\
Jane (NNS) & & 2747 & 549 & 20 \\
Carine & \multirow{2}{*}{55.50} & 4172 & 751 & 18 \\
Darren (NNS) & & 4454 & 846 & 19 \\
Louis & \multirow{2}{*}{34.50} & 3497 & 490 & 14 \\
Karen (NNS) & 2595 & 467 & 18 \\
\hline Total & 2 hrs 8 min15 s & 9796 & 3669 & 17.5 (avg.) \\
\hline
\end{tabular}


Table 4 Words and intonation units by NS and NNS Australian English speakers

\begin{tabular}{lllll}
\hline Participants & Minutes & Words & $\begin{array}{l}\text { Intonation } \\
\text { units }\end{array}$ & $\begin{array}{l}\text { Intonation units } \\
\text { per 100 words }\end{array}$ \\
\hline Daniel (NNS) & \multirow{2}{*}{45.44} & 3951 & 672 & 17 \\
Beth & & 2499 & 450 & 18 \\
Heather & \multirow{2}{*}{36.30} & 2217 & 454 & 20.5 \\
Marie (NNS) & & 3133 & 689 & 22 \\
Len & \multirow{2}{*}{44.44} & 5160 & 826 & 16 \\
Suzanne (NNS) & & 2968 & 505 & 17 \\
\hline Total & 2 hrs 6 min 2 s & 10,052 & 3596 & 18 (avg.) \\
\hline
\end{tabular}

\section{Methodology}

The data was analysed qualitatively using the principles of the sequentialinteractional frameworks of Interactional Sociolinguistics and Conversation Analysis (CA). Both of these frameworks were chosen for the analysis of the data due to their emphasis on the detailed analysis of natural data, and on the social and linguistic meaning created during interaction. I will limit myself to a brief discussion here (cf. Mullan \& Karlsson, this volume for a detailed description of these concepts).

Central to Interactional Sociolinguistics is Gumperz's desire for a "general theory of verbal communication which integrates what we know about grammar, culture and interactive conventions into a single overall framework of concepts and analytical procedures" (1982, p. 4). These concepts are: contextualisation cues (prosody and isolated intonation units); contextual presupposition (assumed background knowledge); and situated inference (understanding the communicative activity and the speaker's actual illocutionary act).

Gumperz observed that in today's multicultural societies, people from distinct linguistic and cultural backgrounds regularly come into contact with each other, and that this can lead to certain communication problems or breakdown (cf. Gumperz's $(1982,1992)$ seminal research into the communication difficulties between speakers of British and Indian English). Although Gumperz's research contained several instances of communication breakdown, my own research contains very few examples of such obvious misunderstandings. With the exception of some instances of minor interactional trouble in my data, the interactions between native and non-native speaker appeared to be largely unproblematic on the surface. Previous studies have shown however, that French and Australian English speakers are sometimes left with a general negative feeling following an interaction with each other (Béal, 2010 inter alia), when the speakers interpret the other's way of speaking from their own perspective.

One of the reasons for this has been found to be the value placed on the expression of opinion in the two cultures (to be discussed further below). For example, in an interesting parallel to Gumperz's (1982) gatekeeper research on British and Indian English speakers in job interviews, Lipovsky (2000) found that Australians speaking French in interview role plays tended to overuse je pense ('I think'), giving their French interviewers the impression that they were unassertive and not 
sure of their abilities. This is an example of the misinterpretation of contextualisation cues by both parties; the Australians used je pense according to their own use of $I$ think, and the French speakers read these cues according to their own use and understanding of je pense.

The principle aim of CA is to discover how participants understand and respond to each other's turns in naturally occurring talk-ininteraction. The central interactional organisation concepts of CA are: turn-taking in interaction; adjacency pairs; preference and preferred responses; recipient-design (where talk is constructed in ways which display an orientation and sensitivity to the interlocutor); and repair.

While it is more common to adopt the TCU (turn construction unit) as the unit of analysis in CA, I have instead used the intonation unit (IU), defined by Du Bois, Schuetze-Coburn, Cumming and Paolino (1993) as "a stretch of speech uttered under a single coherent intonation contour [...] marked by cues such as a pause and a shift upward in overall pitch level at its beginning, and a lengthening of its final syllable” (p. 47). The reasons for choosing the IU over the TCU are briefly the following (cf. also Mullan \& Karlsson, this volume): Chafe (1993) describes IUs as "in a sense what language is all about" (p.37). He points out that if the IU is a verbal representation of what is in the speaker's mind at a certain time, then the speaker's intention must be to convey that idea to the listener; in this way intonation units can reveal how much and what kind of information a speaker can focus on at once (p. 39). This is clearly linked to the CA concept of recipient-design and the sequential nature of coconstruction of discourse in CA and Interactional Sociolinguistics.

Also unlike traditional CA studies, I present some basic frequency counts of IUs and comment clauses. The quantitative data are intended as an illustration of the functions and positions of the comment clauses which have all been analysed individually and qualitatively in context (in accordance with CA). Table 5 presents the overall distribution of the comment clauses under investigation.

Table 5 Distribution of comment clauses by French and Australian English non-native speakers

\begin{tabular}{lll}
\hline & Tokens & Per1000 words \\
\hline I think & 63 & 6.27 \\
je pense & 30 & 3.6 \\
je crois & 27 & 2.6 \\
je trouve & 12 & 1.22 \\
\hline
\end{tabular}

All conversations were transcribed using a combination of the conventions of Conversation Analysis devised by Jefferson (1994), and the University of California, Santa Barbara method of discourse transcription devised by Du Bois et al, (1993); full details of these conventions appear at the end of this chapter. 


\section{Expressing opinions in French and Australian interaction}

Opinions are sometimes expressed so forcefully that they sound like facts. Nothing is a fact unless it can be double-checked, or has been proved beyond doubt. (Wise, 1999, p. 110)

Different ways of speaking in different societies are based on distinctive cultural priorities and values. As Wierzbicka (2006) points out, "ways of thinking which are widely shared in a society become enshrined in ways of speaking” (p. 22). Of particular interest to us here are the interactional styles of French and Australian English speakers, notably the respective value placed on the expression of opinion in interaction.

It has been found that for French speakers exchanging ideas is highly valued - it shows commitment to the conversation by way of involvement with one's interlocutor (Béal, 2010 inter alia; KerbratOrecchioni, 1990). In Béal's (1998) study, the Australian English speakers' reluctance to express opinions led some of the French informants to describe Australians as 'wishy-washy' (p. 6). For example, when discussing their weekend, Béal found that her Australian participants generally preferred to give facts and information about events, where her French participants tended to express opinions and feelings (1992: 29, 35). Béal suggests that French speakers believe that the person asking the question is more interested in the speaker than the facts, and therefore in what the speaker thinks and feels about something, be it negative or positive, and so volunteer their opinions spontaneously (1992: 35).

One of my French NS participants (from Mullan 2007, 2010) felt that he had a duty to express his opinion:

\section{Guillaume: Il faut donner son opinion. Tout le temps. Tout le temps. Si on a quelque chose à dire, il faut le dire. Sinon on fait pas avancer le monde.}

Guillaume: You have to give your opinion. All the time. All the time. If you've got something to say, you have to say it. Otherwise we don't make the world progress.

Where expressing one's opinion is extremely important for French speakers, this is not necessarily always the case for Australian English speakers. While Australians do of course express opinions, this must be done within certain limitations: opinions must not be presented as fact (cf. quotation from Wise above), and they must not be imposed on one's interlocutor (Wierzbicka, 2006, p. 55). This is achieved by prefacing opinions with $I$ think or in my view, thereby implying more detachment from the statement.

As Wierzbicka points out, by overtly marking a statement as our own opinion we are emphasising that it is not fact, and at the same time we are acknowledging that our interlocutor might not be of the same opinion (and has a perfect right not to be). Schiffrin (1990) sees opinions as "free[ing] the speaker [...] from a claim to truth"(p. 245) since they are unverifiable, subjective views - and therefore unavailable for proof - and 
so "another's right to doubt the validity of an opinion cannot be denied" (p. 248).

In his book on (English) conversation, Wardaugh (1985) states that

[i]n general, opinions are not likely to be stated unequivocally and bluntly: we are usually not so 'opinionated'. Instead, we hedge or modify what we say. [...] Unhedged language on important topics is a sure sign of dogmatically held beliefs: $\mathrm{X}$ is right [wrong, good, bad], and so on. [...] But people who insist on constantly using this kind of framing device for statements are likely to be seen as hard and inflexible; they leave little room for cooperation with others who might not share their opinions. (pp , 181-183)

Expressions such as I think "leave the door open to other opinions and tend to promote discussion of any differences that appear to exist rather than to provoke challenges or denials from others" (Wardaugh, 1985, p. 183). As Australian English speakers, we equate being opinionated with an intolerance for differing opinions, and an unwillingness to listen. Two of my participants commented on this:

(2) Fiona: ..... there'll be lots of people you read their opinions (.) when they write to The Age or to the Herald Sun \{Australian newspapers\}(.) whoever they write to (.) editors and they say "(.) this is my opinion and this is the way it is" and you sort of think "mm is that (.)" it's sort of they say it as if it's fact (0.3) erm yeah like very opinionated erm (.) either that or they don't really think it's their business (.) and I think both of those two extremes are really quite unhealthy .....

(3) Kerry: it \{being opinionated \} has a negative connotation for you?

Mark: w- well it does because (1.5) um, you're never go- really going to learn anything new if you're like that. (1.5) like (0.3) you've already decided on everything.

Indeed, it is highly significant that the term opinionated, usually used pejoratively in English to refer to someone who has a tendency to always express strong opinions, has no equivalent in French.

The four comment clauses were originally chosen for investigation on the basis of their prevalence in the data. I think was selected initially, and the French comment clauses were subsequently selected as 'equivalents'. The French and Australian English NS use of these expressions was as follows: 
Table 6 Distributions of comment clauses by French and Australian English NS

\begin{tabular}{lll}
\hline & Tokens & Per 1000 words \\
\hline I think & 281 & 8.8 \\
je pense & 133 & 3.2 \\
je crois & 36 & 0.9 \\
je trouve & 59 & 1.4 \\
\hline
\end{tabular}

From this it can be seen that $I$ think is used almost twice as often in the Australian English data than the three French comment clauses combined. This supports what we have said about the importance of mitigating opinions in English.

\section{Core meanings of the comment clauses}

It has been suggested that discourse markers lack semantic content and do not contribute to "the substance of what the discourse ends up having said” (Schegloff, 1981, p. 74). This is relevant to the instances in my data where a comment clause primarily performs an organisational role in discourse (see below). I take the view of Wierzbicka (1986a, p. 597) however, who assumes that all words have meaning, and that the meaning of a word determines its range of use. (Indeed, if a word has no semantic content, it is difficult to see how it has a use at all.) As Stenström (1997) states in her study on comment clauses: "the pragmatic function of I think [...] in spoken interaction is influenced, first, by the inherent semantic content of the verb [...]" (p. 294, my emphasis). It is this inherent semantic content I am referring to when I use the term core meaning.

Having argued that the core meaning of a word or expression is always present however, I acknowledge that this is at times more or less disregarded in favour of its function as a discourse marker. As Schourup (1985) says, "the more an expression is used routinely, the more it is apt to lose contact with its literal meaning” (p. 7). In the cases of I think, je pense, je crois and je trouve, this is supported by the reduced phonology where it appears as a discourse organiser (cf. following section), indicating that the focus is not on the expression itself, but on the following discourse.

This is not to suggest that the discourse marker loses any of its meaning, simply that the speaker is less conscious of it. Indeed, the fact that there are three expressions in French which equate to $I$ think is evidence that discourse markers are not semantically empty, and illustrates the fact that these comment clauses are non-isomorphic (although naturally with some overlap), both within French, and across the two languages. The fact that speakers choose one of these expressions over the other two at any one time is highly significant, since each expression must have an individual meaning more suited to the context at the time. ${ }^{5}$

\footnotetext{
5 This can be seen in Table 9 where details of the occurrences of these expressions per French NS are presented. Although the basic patterning is very similar, there is still some individual variation across speakers, which is to be expected. This does not mean that speakers show a personal preference for one term over another in the same way as one might show a preference for certain lexical items over others, but that the viewpoints
} 
It is important to mention here that the following core meanings proposed for the four comment clauses under investigation are in relation to each other only; i.e. one could argue that the proposed core meaning for I think could - without further analysis - also apply to other similar epistemic expressions such as I guess, I suspect, I reckon etc. Since the purpose of this analysis is not to show how I think differs semantically from other epistemic expressions in English, but from the three expressions considered the closest equivalents in French, the reader should consider the core meanings proposed here as a subset in opposition to each other only. ${ }^{6}$

\section{I think}

In using I think the speaker wishes to positively assert or claim a particular viewpoint towards a proposition while disclaiming knowledge of it. The speaker thereby uses this expression as a hedge to distinguish facts from opinions, which is culturally important for Australian English speakers.

\section{je pense}

This element of distinguishing facts from opinions is absent from the core meaning of je pense, which I propose is expressing an opinion based on reflection, where the speaker wishes to positively assert or claim a particular stance towards a proposition. The verb penser ('to think') is connected to cogitation and reflection, and suggests a viewpoint based on facts, known or inferred events. The core meaning of je pense therefore comprises an intellectual process, intellectualism in turn being very important for French speakers.

je crois

I propose that the core meaning of je crois is that of expressing a belief - or conviction, and I distinguish this from expressing an opinion as being something more fundamental to, and strongly held by, the speaker. A belief is often based on personal values, usually acquired through education and acculturation.

\section{je trouve}

The core meaning of je trouve is proposed as expressing an opinion discovered through personal experience, whether by explicit or inferred discovery. ${ }^{7}$ [6] (Since je trouve limits the validity of the opinion to one's own individual experience, it cannot be used to express doubt in the same way as je pense and je crois; cf. functions below.)

These core meanings are summarised in Table 7.

expressed will at times be based on reflection, on belief, or on experience; these are the factors which will determine how the viewpoint is expressed.

6 The justification and explanation for the core meanings proposed here are presented in full in Mullan (2010).

7 See Mullan (2010) for a detailed discussion of (non-grammatical) evidentiality in French, as illustrated through the comment clause je trouve. 
Table 7 Core meanings of I think, je pense, je crois and je trouve

\begin{tabular}{ll}
\hline Comment clause & Core meaning \\
\hline I think & disclaims knowledge of the upcoming proposition \\
je pense & positively asserts a particular stance towards a proposition \\
& based on reflection \\
je crois & expresses a belief or conviction \\
je trouve & expresses an opinion discovered through personal \\
& experience
\end{tabular}

While it will be seen in the following section that je pense and je crois can be used to indicate uncertainty in discourse, the core meanings proposed for je pense, je crois (and je trouve) do not include disclaiming knowledge of the facts, as in the case of $I$ think. This is supported by the fact that these verbs of opinion - or verbes de pensée (literally 'verbs of thought') as they are known: penser, croire and trouver - all require a subjunctive construction when expressed in the negative, as an overt marker of doubt.

Briefly, the subjunctive mood is usually required when expressing subjectivity in French; the subjunctive appears in the subordinate clause following a verb implying necessity, desire, emotion, and doubt (as well as certain other constructions). For example:

Il est possible qu'il dorme (subjunctive).

It is possible that he is sleeping.

The fact that penser, croire and trouver do not require the subjunctive in the affirmative is evidence that they do not imply doubt to the same degree as I think.

\section{Functions of the comment clauses in the NS data}

The comment clauses were all found to be multifunctional, and the following functions identified, as part of the larger study on native speaker discourse (Mullan 2007, 2010). The functions were found to apply to both the French and Australian English data. These functions in discourse are specifically a) organisational, b) semantic and c) pragmatic (cf. also Mullan \& Karlsson, this volume) ${ }^{8}$.

a) The organisational functions are used as "road signs in conversational exchanges” (Wierzbicka 1986b, p. 524), consisting specifically of

- marking a boundary in discourse, e.g. to initiate a topic, frame a side sequence, or to sum up in discourse

- marking a new or different perspective from the prior turn (or speaker)

- indicating on-line planning

\footnotetext{
8 These terms correspond roughly to the three components of Redeker's (1991) model of discourse coherence: textual (sequential level), semantic (locutionary level), and pragmatic (illocutionary level). This is also similar to Halliday's (1994, 2004) systemic functional linguistic terms: textual (organising information), ideational (expressing propositional content) and interpersonal (expressing speaker involvement or attitude).
} 
- marking finality to a proposition (IU-final position)

- signalling turn completion and pursuing speaker response (turn-final position)

b) The semantics of the four comment clauses therefore involve

- expression of opinion

- expression of doubt

There will of course be instances where the speaker appears to be expressing both an opinion and some doubt, as in the following example.

(4) Kerry: and is it athe expression to sit on the fence negatively valued-- evaluated, [in Australian]

Heather: [mm. can be.]

Kerry: culture?

Heather: can be. (.) can be I think. maybe. because, (.) well not strongly.

Here Heather is expressing her opinion on whether the expression to sit on the fence is viewed negatively or not, but there is also an indication that she is not sure of the validity or truth of the proposition. This can be seen through the use of the other hedges such as can be, maybe, and the qualifier well not strongly.

c) The comment clauses under investigation may also have a pragmatic (face-saving) function: this can be achieved by indicating doubt or an opinion, in order to save the face - of either the speaker or the interlocutor or both - depending on the situation.

It should be pointed out here that being multifunctional, the comment clauses may all perform more than one of the above functions at any one time. For this reason I refer to the primary or dominant function of the comment clauses in some cases. Where the expression is performing as an organisational discourse marker, the prosody and context may also indicate an expression of speaker opinion or doubt, which in turn may be intended as a face-saving device. However, a careful analysis will reveal the dominant function in most cases. As Redeker (1991) says, "one [component] will usually dominate and suggest itself as the most relevant linkage of this utterance to its context" (p. 1168).

Figure 1 illustrates the preceding discussion by representing the overarching semantic invariant of all four expressions as speaker stance, the core meaning of each individual expression, and the functions of each expression in discourse: organisational, semantic and pragmatic. Where the function of the expression is primarily semantic, this can be to express an opinion or doubt (or a combination of both), except in the case of je trouve which cannot imply doubt. 
Figure 1 Core meanings and functions of I think, je pense, je crois and je trouve

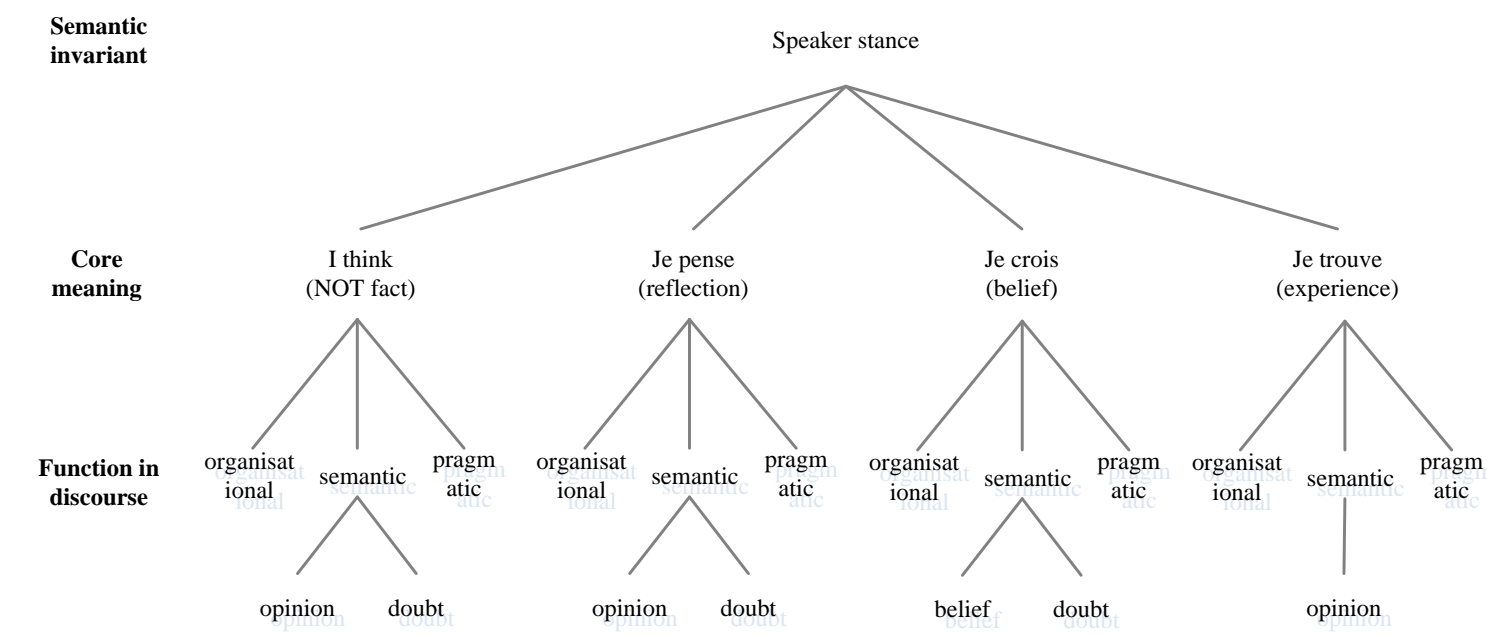

Prosody and IU-position (and the corresponding IU-contour) were the consistent primary factors involved in determining the exact functions of the comment clauses in interaction, although the context was also important.

The prosody of the comment clauses as organisational discourse markers has been shown to involve acceleration and phonological reduction (Kärkkäinen, 2003; Mullan 2010). This is because the focus is not on the personalisation of the comment clause itself, but on what follows. So the prosody of $I$ think as an organisational discourse marker will typically be pronounced as something like [ahIn], where the subject pronoun $I$ is almost inaudible. The corresponding acceleration of the French comment clauses results in je pense, je crois and je trouve reducing to [Zpãs], [ZkRwa] and [Ztruv] respectively (although the consonants in the French comment clauses do not undergo such a radical alteration as those in the English $I$ think, where the th and $k$ essentially disappear. (This is evidence that the French comment clauses have not grammaticised into discourse markers to the same extent as I think, since the phonological reduction is not as advanced; (cf. discussion on grammaticisation Mullan \& Karlsson, this volume).

Where the comment clause displays level stress and no reduction however, this typically indicates that the expression of opinion is the primary function. Where there is a fall-rise intonation, the primary function of the comment clause is to indicate some doubt as to the veracity of the proposition.

The prosodic features described above are applicable to both English and French, and therefore allowed for a comparable analysis of the NS and NNS data. The frequencies of the functions in the NS data are detailed below in Table 8 . 
Table 8 - Functions of I think, je pense, je crois and je trouve in the NS data

\begin{tabular}{|c|c|c|c|c|}
\hline Functions & I think & je pense & je crois & je trouve \\
\hline \multicolumn{5}{|l|}{ Organisational: } \\
\hline - to mark a boundary in discourse & 129 (45.9\%) & $17(12.8 \%)$ & $18(50 \%)$ & $6(10.2 \%)$ \\
\hline - to sum up in discourse & $16(5.7 \%)$ & $13(9.8 \%)$ & $2(5.6 \%)$ & $6(10.2 \%)$ \\
\hline - to mark a new or different & $17(6 \%)$ & $5(3.8 \%)$ & $2(5.6 \%)$ & \\
\hline perspective from the prior turn & & & & \\
\hline - in on-line planning & $14(5 \%)$ & $20(15 \%)$ & $3(8.3 \%)$ & $8(13.6 \%)$ \\
\hline - $\quad$ to mark finality (IU-final) & $5(1.8 \%)$ & $11(8.3 \%)$ & $2(5.6 \%)$ & $2(3.4 \%)$ \\
\hline $\begin{array}{l}\text { - to signal turn completion (turn- } \\
\text { final) }\end{array}$ & $3(1.1 \%)$ & $5(3.8 \%)$ & & $2(3.4 \%)$ \\
\hline Subtotal & $184(65.5 \%)$ & $71(53.4 \%)$ & $27(75 \%)$ & $24(40.7 \%)$ \\
\hline \multicolumn{5}{|l|}{ Primarily semantic: } \\
\hline - to express doubt & $11(3.9 \%)$ & $3(2.2 \%)$ & $3(8.2 \%)$ & \\
\hline - to express speaker opinion & $85(30.2 \%)$ & $59(44.5 \%)$ & $6(16.5 \%)$ & $35(59.3 \%)$ \\
\hline Subtotal & $96(34.1 \%)$ & $62(46.6 \%)$ & $9(25 \%)$ & $35(59.3 \%)$ \\
\hline $\begin{array}{l}\text { Primarily pragmatic: } \\
\text { - to save face (of the speaker, the } \\
\text { addressee, or both) }\end{array}$ & $1(0.4 \%)$ & & & \\
\hline Subtotal & $1(0.4 \%)$ & & & \\
\hline Total & $281(100 \%)$ & $133(100 \%)$ & $36(100 \%)$ & $59(100 \%)$ \\
\hline
\end{tabular}

Since the functions of the four comment clauses were found to be similar in both French and Australian English, we can hypothesise that the NNS will use the comment clauses for the same functions in their L2 as their L1. This was indeed found to be the case, although there were some important differences in the frequencies of these functions. As might be expected, there were also significant differences between NS and NNS usage in the total number of occurrences of these comment clauses, and in the prosody of the comment clauses themselves. These will be discussed in the following sections, and examples from the data provided.

\section{Functions of the comment clauses in the NNS data}

All functions of the four comment clauses identified in the NS data were found to occur in the NNS data, with the exception of the pragmatic facesaving function. Since this occurred only once as the primary function in the NS data, this cannot be considered a significant difference. Examples of all of the functions follow.

The first example illustrates the use of I think to mark a boundary in discourse, in particular to introduce a new topic. Daniel and Beth have been talking about racism, and Daniel is referring to the far right political party in France, Le Front National.

(5) Daniel: and I thi- it's funny, 'cause in France this -- this national, er political party, erm got a lot of success, but mainly with peoples coming from countryside, they never seen an African or whatever, they are just living in their small farm, I don't know, they're not thinking. 
Kerry: mm.

Daniel: it's just very scary.

Beth: yeah.

Kerry: mm.

Daniel: and after, something I- I think er, young people, when er, young kids arrive, 10 in Australia, come in 10 years old, coming from another country, I think it's ???? they still able to learn the language and mix with other [people,]

Beth:

[mm.]

Daniel: I don't know, (0.3) when you're older it's not so easy,

Beth: no.

Daniel: but ??? and after, I think when you -- you're far away from your country, if you hasn't -- if you haven't really choose to immigrate, or if you have no choice because of situation economical .....

His use of and after, something I- I think er, young people clearly introduces a new topic. This idea of young children arriving in Australia is not related to the previous topic of the political party. This can also be seen in Daniel's falling intonation contour after they're not thinking. and again following it's just very scary. When there is no speaker uptake from anyone else, he perhaps feels obliged to continue speaking and finds something new to talk about. His two instances of and after, immediately prior to his uses of I think, also indicate that these are new topics, as this is a transference from French, where the expression et après ('and after') can be used to move on to a new topic.

Example (6) illustrates the use of a comment clause to sum up in discourse. I have asked the participants whether they feel there is any racism in Australia. Darren takes the first turn and speaks for five whole minutes on this topic, with minimal feedback from his interlocutor. He ends his monologue with:

Darren: et $>$ j'crois que $<$ c'est un -- ouais, c'est un grand problème en Australie, on sait pas comment euh, (0.3) comment surmonter ce défit.

Darren: and >j'crois que $<$ it's a -- yeah, it's a big problem in Australia, we don't know how er, (0.3) how to overcome this challenge.

This reduced and accelerated instance of je crois is used to summarise Darren's contribution to the topic. He repeats it's a -- yeah, it's a (big problem), this repetition being another indicator of summing up.

The next example is the use of I think to mark a difference from the prior turn. The participants have been talking about stereotypes.

(7) Len: I-- I think that's -- that's starting to become a pretty common thought about like, (.) um, especially, I mean it's always -- and people always sort of put, um Asians and stuff, into this little bracket that's = 
Suzanne:

Len: you know, that you know, want to be successful and

Suzanne: [yeah]

Len: [and] take us, take over Australia,

Suzanne: @@

Len: and er -- and soon you know, they'll come here in boats from Indonesia and hooligans um -- you know, it's pretty scary.

Suzanne: well I think it's international, like we've got a lot of Asian migrants in France as well and this -- they've got this stereotype to be hard workers

Len: $\quad[\mathrm{mm}]$

Suzanne: [as well] over there.

Len begins by saying that certain stereotypes are becoming common, and then uses irony when he refers to people taking over Australia; he himself does not think this way, but is mocking people who do. This is clear from Len's intonation, and Suzanne understands that this is what he is doing, and responds to his use of humour with laughter. When Len has finished speaking, Suzanne says well, I think it's international. This use of I think is to mark a difference from the prior turn. Len has intimated that this situation is pertinent to Australia, but Suzanne wishes to point out that they have a similar situation with such stereotypes in France. It has been noted that dispreferred responses in English are typically prefaced with hedges such as ah, well, pauses, hesitations, etc. (Pomerantz, 1984, p. 72, 77), and this is illustrated here with Suzanne's use of well.

In the following example, we see an instance of je pense used in online planning. Jane and Christine have been talking about Jane's experience as an exchange student in France when she was at secondary school, so this topic change seems somewhat out of place. It is possible that Jane is thinking about an earlier topic and trying to link her comments back to this. From the pauses and hesitation markers, restarts and truncated intonation units, it is clear that she is having trouble formulating her thoughts. This is supported by her utterance of what was I going to say?

(8) Jane: et quoi encore -- je pense que $j$ 'suis (1.0) je pense que j'ai des idées un peu um, (1.0) um, (2.0) (Hx), (1.0) c'est pa::::s, (0.3) je suis pas neutre parce que je -- je fais des études sur le -- le français,

Kerry: $m m$.

Jane: $\quad$ et (.) sur le tu et le vous? (0.3) et um, moi je -- j'pense que -- qu'est-ce que j'allais dire? (0.4) j'pense que les (0.3) les Français, (1.0) c'est ce que j'ai remarqué avec le -- l'usage des pronoms .....

Jane: and what else -- je pense que I'm (1.0) je pense que I've got ideas a bit um, (1.0) um, (2.0) (Hx), (1.0) it's no::::t, (0.3) I'm not neutral because I -- I'm doing a study on -French, 
Kerry: $\mathrm{mm}$.

Jane: $\quad$ and (.) on tu and vous? (0.3) and um, moi je -- j'pense que -- what was I going to say? $(0.4) j$ jeense que the $(0.3)$ the French, (1.0) what I've noticed with the -- the use of pronouns .....

The following extract between Jane and Christine contains an example of je crois used to mark finality. We have been discussing cultural differences, and Jane has said that one needs to harden up when in France to cope with what could be construed as insensitive behaviour.

(9) Kerry: et tu arrives à être plus dure en français? (0.4) moi oui, moi

j'ai toujours trouvé plus facile, c'est -- parce que -- c'est comme si c'est pas moi qui parle, (0.3) je -- je peux -- je

(.) [ouais.]

Jane: [ouais,] j'ai l'impression de jouer un rôle (.) [quand]

Kerry:

Jane: je parle français (0.3) [ouais.]

[mm.]

Kerry: [ouais.]

Jane: je suis différente j'crois.

Kerry: ah ouais, (0.3) et toi tu es différente en anglais?

[tu trouves]?

Christine: [ouais]

Kerry: and do you manage to be harder in French? (0.4) I do, I’ve always found it easier, it's -- because -- it's like it's not me who’s speaking, (0.3) I -- I can -- I (.) [yeah.]

Jane:

impression I'm playing a part (.) [when] [yeah,] I get the

Kerry: [mm.]

Jane: I speak French (0.3) [yeah.]

Kerry: [yeah.]

Jane: I'm different $j$ 'crois.

Kerry: oh yeah (0.3) and are you different in English? [do you think]?

Christine:

[yeah]

In answer to my question, Jane agrees that she feels like she is playing a part when she speaks French, and sums up with je suis différente je crois. Her je crois is slightly reduced, thereby indicating its function as an organisational discourse marker, and her falling intonation afterwards indicates finality. I understand this as a marker of finality and put the question to Jane's interlocutor now instead.

Example (10) illustrates an instance of I think used to mark finality and signal turn completion. Daniel has been talking about the situation in the French Basque country.

(10) Daniel: but in France they never had Franco, so they are very very hard -- harder in Spain because of that, I think, 
Kerry: right.

Daniel: more than in France, and er they -- and in another way, they didn't wanted to have people fighting in France, because all people who used to fight in Spain, if they get in trouble, could go in France, you know, it's like on the war, it's-- you got the first line, but after you can come back and have a rest, that's why, I think.

Beth: mm. that's interesting, yeah, I hadn't ever thought about the .....

Daniel's first instance of I think shows that he has not finished speaking (cf. the continuing intonation contour); his level intonation shows that he is expressing an opinion. However, his second instance of $I$ think is followed by a falling intonation contour which clearly marks finality to his turn, as well as signalling turn completion. This is understood by Beth, who then takes the floor.

Example (11) illustrates the use of $I$ think to indicate some doubt as to the veracity of a proposition. I have asked Marie, a native French speaker, what the expression donner une réponse de Normand ('to give a Norman's response', i.e. maybe, maybe not) means. Marie firstly replies that she does not know, but then goes on to guess.

(11) Kerry: ok so you -- do you know, Marie, the expression

"donner une réponse de Normand"?

Marie: er no, but $I$ think it might be like er, a story that ends like a fish --tail? End fish that means, no? well,

Kerry: dunno.

Marie: ok well, [you don't know this,]

Kerry: [I don't know.

Marie: finir en queue de poisson.

Kerry: I don't know that expression.]

Marie: [that means it doesn't finish,] there's no sense in the end of the story.

Marie attempts a guess at the meaning of the expression, but it is clear from her answer that she is not sure. In addition, her utterance of I think shows a fall-rise intonation, also indicating some uncertainty.

The final example illustrates three instances of je trouve marking speaker opinion. In this example Jane is talking about what she finds sexist in French culture.

(12) Jane: une -- une autre différence que je trouve très marquée entre les deux -- cultures, (0.5) c'est le, (1.0) le sexisme, (.) ou ce que je trouve sexiste [dans (.) dans la]

Christine: $\quad[\mathrm{mm} \mathrm{mm}$.]

$$
\text { [mm } \mathrm{mm} \text {.] }
$$

Jane: $\quad$ culture française, moi je trouve que les femmes, (1.5)

elles, (0.3) par exemple si tu es dans le métro (.) à

Paris, tu peux -- tu peux pas regarder un homme, (.)

c'est comme une invitation. 
Jane: an -- another difference that I find very marked between the two-- cultures, (0.5) is the, (1.0) the sexism, (.) or what I find sexist [in ..in] French culture,

Christine: [mm mm.]

Jane: $\quad$ moi je trouve que women, (1.5) they, (0.3) for example if you are in the metro (.) in Paris, you can't -- you can't look at a man home, (.) it's like an invitation.

Jane uses je trouve three times to mark speaker opinion. Her intonation is level and unreduced, and the addition of moi in front of the third instance is another indicator of speaker opinion. This use of moi in front of the subject pronoun je is extremely common in French conversation. It has the effect of emphasising the subject pronoun, thereby asserting the speaker's position, and corresponds to something like 'this is what I think', which is used much less often in English. The surrounding context also indicates to the expression of opinion here, as Jane goes on to talk at some length about what she sees as sexism in France; this is a topic she feels quite strongly about. The sense of personal experience is clear in these instances of je trouve too, where Jane is clearly relating experiences she had when living in France.

As stated, the above functions were all found to occur in the NS and NNS discourse. Several significant differences were found in the frequency of the functions however, as shown in Table 9.

Table 9 Functions of I think, je pense, je crois and je trouve in the NNS data

\begin{tabular}{|c|c|c|c|c|}
\hline Functions & I think & je pense & je crois & je trouve \\
\hline \multicolumn{5}{|l|}{ Organisational: } \\
\hline - to mark a boundary in discourse & $22(35 \%)$ & $22(73 \%)$ & $14(52 \%)$ & $1(8 \%)$ \\
\hline - to sum up in discourse & $3(5)$ & $2(6.6 \%)$ & $4(15 \%)$ & \\
\hline - to mark a new or different & $4(6 \%)$ & $1(3.3 \%)$ & $3(11 \%)$ & \\
\hline perspective from the prior turn & & & & \\
\hline - in on-line planning & $3(5 \%)$ & $1(3.3 \%)$ & & \\
\hline - $\quad$ to mark finality (IU-final) & $1(1.6 \%)$ & & $2(7.4 \%)$ & \\
\hline $\begin{array}{l}\text { - to signal turn completion (turn- } \\
\text { final) }\end{array}$ & $1(1.6 \%)$ & & & \\
\hline Subtotal & $34(54 \%)$ & $26(87 \%)$ & $23(85 \%)$ & $1(8 \%)$ \\
\hline \multicolumn{5}{|l|}{ Primarily semantic: } \\
\hline - to express doubt & $2(3 \%)$ & & $1(3.7 \%)$ & \\
\hline - to express speaker opinion & $27(43 \%)$ & $4(13.3 \%)$ & $3(11.1 \%)$ & $11(92 \%)$ \\
\hline Subtotal & $26(46 \%)$ & $4(13 \%)$ & $4(15 \%)$ & $11(92 \%)$ \\
\hline \multicolumn{5}{|l|}{$\begin{array}{l}\text { Primarily pragmatic: } \\
\text { - to save face (of the speaker, the } \\
\text { addressee, or both) } \\
\text { Subtotal }\end{array}$} \\
\hline Total & $63(100 \%)$ & $30(100 \%)$ & $27(100 \%)$ & $12(100 \%)$ \\
\hline
\end{tabular}

The main differences between Tables 8 and 9 are summarised below in Table 10. From this, it can be seen that the NNS used je pense and je crois as organisational discourse markers more often than the native French speakers (particularly to mark a boundary in discourse); this could be due to the transference of the extensive use of $I$ think as an organisational discourse marker in Australian English. There is a significant difference in the use of je trouve as organisational however: 
whereas the native French speakers in my data used je trouve as an organisational discourse marker almost half of the time, it seems that the NNS considered je trouve to be predominantly a marker of speaker opinion, This could be due to the fact that the NNS know that je trouve cannot express any doubt, and for this reason, they perhaps consider this comment clause as less like I think in Australian English, and therefore less able to perform as an organisational discourse marker.

On the other hand, the NNS used I think somewhat less often as an organisational discourse marker than the native Australian English speakers; again, this could be due to a transference from their L1, where two of the three French comment clauses (je pense and je trouve) are not used as organisational discourse markers as often as I think in English.

Table 10 Functions of I think, je pense, je crois and je trouve in the NS and NNS data

\begin{tabular}{|c|c|c|c|c|c|c|c|c|}
\hline \multirow{2}{*}{ Functions } & \multicolumn{2}{|c|}{ I think } & \multicolumn{2}{|c|}{ je pense } & \multicolumn{2}{|c|}{ je crois } & \multicolumn{2}{|c|}{ je trouve } \\
\hline & NS & NNS & $N S$ & NNS & NS & NNS & NS & NNS \\
\hline Organisational: & $\begin{array}{l}184 \\
(66 \%)\end{array}$ & $\begin{array}{l}34 \\
(54 \%)\end{array}$ & $\begin{array}{l}71 \\
(53 \%)\end{array}$ & $\begin{array}{l}26 \\
(87 \%)\end{array}$ & $\begin{array}{l}27 \\
(75 \%)\end{array}$ & $\begin{array}{l}23 \\
(85 \%)\end{array}$ & $\begin{array}{l}24 \\
(41 \%)\end{array}$ & $1(8 \%)$ \\
\hline $\begin{array}{l}\text { Primarily } \\
\text { semantic: }\end{array}$ & $\begin{array}{l}96 \\
(34 \%)\end{array}$ & $\begin{array}{l}29 \\
(46 \%)\end{array}$ & $\begin{array}{l}62 \\
(47 \%)\end{array}$ & $4(13 \%)$ & $9(25 \%)$ & $4(15 \%)$ & $\begin{array}{l}35 \\
(59 \%)\end{array}$ & $\begin{array}{l}11 \\
(92 \%)\end{array}$ \\
\hline $\begin{array}{l}\text { Primarily } \\
\text { pragmatic: }\end{array}$ & $\begin{array}{l}1 \\
(0.4 \%)\end{array}$ & & & & & & & \\
\hline Total & $\begin{array}{l}281 \\
(100 \%)\end{array}$ & $\begin{array}{l}63 \\
(100 \%)\end{array}$ & $\begin{array}{l}133 \\
(100 \%)\end{array}$ & $\begin{array}{l}30 \\
(100 \%)\end{array}$ & $\begin{array}{l}36 \\
(100 \%)\end{array}$ & $\begin{array}{l}27 \\
(100 \%)\end{array}$ & $\begin{array}{l}59 \\
(100 \%)\end{array}$ & $\begin{array}{l}12 \\
(100 \%)\end{array}$ \\
\hline
\end{tabular}

Table 10 also illustrates the differences in the NS and NNS use of the comment clauses to express an opinion. The NNS used je pense and je crois rather less often than the native French speakers to express an opinion; this is of course a consequence of the NNS using these expressions as organisational discourse markers more often than the native speakers. Again, the greatest difference comes in the use of je trouve, which the NNS used overwhelmingly to express an opinion much more so than the native speakers, who also frequently use je pense to express an opinion.

It is also telling that the NNS used I think to express an opinion significantly more often than the native Australian English speakers; this is clearly a transference from their L1 (especially their use of je pense as NS to express an opinion, which shows an almost identical frequency to their NNS use of $I$ think for the same purpose).

It is difficult to draw any firm conclusions as to whether the increased or decreased NNS use of these comment clauses (as compared to NS use) for a particular function has any effect on the NS interlocutor. Since we cannot know for sure how aware a native speaker is of these functions in their L1 discourse, without further investigation it is impossible to determine whether a native speaker has any awareness of such differences in their non-native interlocutor's L2 discourse. A native speaker is more likely to be affected by the overall frequency of use and the prosody of the comment clauses, both of which will be discussed in the following sections. 


\section{Occurrences of the comment clauses}

The breakdown of the occurrences of the comment clauses by individual NS and NNS is detailed in Tables 11 to 14 . Table 11 details the occurrences of the English expressions by Australian English NS. I have included the expressions I believe and I find by way of comparison with the French expressions je crois and je trouve respectively (which can be translated as I believe and I find on occasion).

Table 11 Occurrences of I think, I believe and I find by Australian English NS; normalised (1000 words) and raw frequencies

\begin{tabular}{|c|c|c|c|c|c|c|c|c|c|c|}
\hline & Lisa & Fiona & Heather & Beth & Ken & Natalie & Kylie & Mark & Len & Total \\
\hline I think & $\begin{array}{l}2.6 \\
(51)\end{array}$ & $\begin{array}{l}7.5 \\
(31)\end{array}$ & $\begin{array}{l}13.5 \\
(30)\end{array}$ & $\begin{array}{l}12.4 \\
(31)\end{array}$ & $\begin{array}{l}6.2 \\
(24)\end{array}$ & $8.7(30)$ & $\begin{array}{l}8.8 \\
(37)\end{array}$ & $\begin{array}{l}2.6 \\
(6)\end{array}$ & $\begin{array}{l}7.9 \\
(41)\end{array}$ & $\begin{array}{ll}8.8 \\
(281)\end{array}$ \\
\hline I believe & 0 & 0 & $0.5(1)$ & 0 & 0 & 0 & 0 & 0 & 0 & $0.5(1)$ \\
\hline I find & $\begin{array}{l}0.5 \\
(2)\end{array}$ & $0.2(1)$ & 0 & $0.8(2)$ & $\begin{array}{l}0.3 \\
(1)\end{array}$ & 0 & 0 & 0 & $\begin{array}{l}0.2 \\
(1)\end{array}$ & $0.2(1)$ \\
\hline I reckon & 0 & $0.5(2)$ & 0 & 0 & 0 & 0 & $\begin{array}{l}0.2 \\
\text { (1) }\end{array}$ & $\begin{array}{l}0.9 \\
(2)\end{array}$ & $\begin{array}{l}0.8 \\
(4)\end{array}$ & $0.3(9)$ \\
\hline I guess & $\begin{array}{l}0.7 \\
\text { (3) }\end{array}$ & 0 & 0 & $1.2(3)$ & $\begin{array}{l}0.3 \\
(1) \\
\end{array}$ & $2.6(9)$ & $\begin{array}{l}0.7 \\
\text { (3) }\end{array}$ & $\begin{array}{l}0.9 \\
\text { (2) }\end{array}$ & $\begin{array}{l}1.2 \\
\text { (6) }\end{array}$ & $\begin{array}{l}\mathbf{0 . 8} \\
(27)\end{array}$ \\
\hline
\end{tabular}

The table shows that the native speakers used I think on average 8.8 times per 1000 words, I believe 0.05 times and I find 0.2 times. It is clear that the latter two expressions did not occur frequently in my data (and the highest use of one of these - I find - was in fact by a French NS; cf. Table 12). I have also included the expressions I reckon and I guess as an interesting comparison with $I$ think. These two expressions also show a low frequency, with I guess appearing more frequently than I reckon. (This is particularly interesting since the expression I guess is often considered more typical of American English, ${ }^{9}$ and I reckon as being a typically Australian English expression.)

Although belief and personal experience are of course both extremely familiar concepts to Australian English speakers, it is culturally highly significant that we rarely employ the expressions I believe and I find to express our opinions (only two and seven instances respectively occurred in my NS data), but we are instead far more likely to choose the more neutral - less binding - expression which distinguishes fact from opinion: I think - even where personal experience is involved.

By way of comparison, Table 12 illustrates the use of the same expressions by French NS using English.

Table 12 Occurrences of I think, I believe and I find by Australian English NNS; normalised (1000 words) and raw frequencies

\begin{tabular}{lllll}
\hline & Marie & Suzanne & Daniel & Total \\
\hline I think & $6.7(21)$ & $1.3(4)$ & $9.6(38)$ & $\mathbf{6 . 3 ( 6 3 )}$ \\
I believe & $0.3(1)$ & 0 & 0 & $\mathbf{0 . 1}(\mathbf{1})$ \\
I find & 0 & 0 & $2(7)$ & $\mathbf{0 . 7}(7)$ \\
I reckon & 0 & 0 & 0 & $\mathbf{0}$ \\
I guess & $1(3)$ & $1(3)$ & 0 & $\mathbf{6 ( 6 )}$ \\
\hline
\end{tabular}

The Australian English NS all used I think to varying degrees, with Daniel showing the highest usage and Suzanne showing a very low usage

\footnotetext{
${ }^{9}$ Cf. Kärkkäinen (2007) on I guess in conversational stancetaking.
} 
of this expression. Daniel's use of nine tokens of I think per 1000 words is quite similar to (or higher than) most of the Australian English NS. While Marie's usage of I think is lower, it is also similar to one NS's usage (and higher than another; cf. Table 11). Daniel is also the only speaker to use $I$ find; his usage of this expression may well be a direct transference from French. As could be expected, the native French speakers also showed a low usage of I guess, and there were no tokens of I reckon.

Table 13 illustrates the occurrences of je pense, je crois and je trouve by individual French NS.

Table 13 Occurrences of je pense, je crois and je trouve by French NS; normalised (1000 words) and raw frequencies

\begin{tabular}{lllllllllll}
\hline & Luc & Vincent & Céline & Bernadette & Irène & Guillaume & Louis & Carine & Christine & Total \\
\hline je & 3.4 & $3.6(18)$ & $1.8(7)$ & $2.9(18)$ & 3.1 & $4.2(20)$ & 4.3 & $2.2(9)$ & $4(14)$ & 3.2 \\
pense & $(13)$ & & & & $(19)$ & & $(15)$ & & & $(\mathbf{1 3 3 )}$ \\
je & 1 & $0.8(4)$ & $0.5(2)$ & $1.5(9)$ & 0.5 & $0.4(2)$ & 0.6 & $1.9(8)$ & $0.6(2)$ & $\mathbf{0 . 9}$ \\
$\quad$ crois & $(4)$ & & & & $(3)$ & & $(2)$ & & & $(\mathbf{3 6})$ \\
je & 0.3 & $0.2(1)$ & $1.3(5)$ & $1(6)$ & 3.2 & $2.1(10)$ & 1.4 & $0.5(2)$ & $2.5(9)$ & $\mathbf{1 . 4}$ \\
trouve & $(1)$ & & & & $(20)$ & & $(5)$ & & & $(59)$ \\
\hline
\end{tabular}

Je pense is the most frequent expression of the three, and occurs three and a half times more often than je crois. There is some variety in usage of the three expressions across the native French speakers. It must be remembered that these individual differences do not mean that some speakers prefer one term to another, but that the viewpoints expressed will be based on reflection, belief, or experience; this is what will determine which expression is the most appropriate at the time.

By way of comparison, table 14 illustrates the use of je pense, je crois and je trouve by the French NNS.

Table 14 Occurrences of je pense, je crois and je trouve by French NNS; normalised (1000 words) and raw frequencies

\begin{tabular}{lllll}
\hline & Karen & Darren & Jane & Total \\
\hline je pense & 0 & 0 & $10.9(30)$ & $\mathbf{3 . 1 ( 3 0 )}$ \\
je crois & $1.2(3)$ & $3.4(15)$ & $3.3(9)$ & $\mathbf{2 . 8 ( 2 7 )}$ \\
je trouve & 1.2 & $0.45(2)$ & $2.55(7)$ & $\mathbf{1 . 2 ( 1 2 )}$ \\
\hline
\end{tabular}

It can be seen that only Jane (an Australian recently returned from ten months' study in France) follows the pattern established by the native French speakers, i.e. where je pense is favoured and occurs much more often than je crois. She is also the only speaker to use je trouve to any extent. In a striking contrast, the other French NNS do not use je pense at all; Darren relies instead on je crois, and Karen hardly uses either expression at all. Both Jane and Darren use je crois more than any native French speaker.

There are two possible reasons for this patterning. Firstly, Darren's (and Jane's) use of je crois as more of a discourse marker could be a transfer from Australian English; perhaps they consider je crois the closest equivalent of $I$ think in that it can often express uncertainty, and perhaps they see this as being the closest to the core meaning of I think, where we are disclaiming knowledge of our proposition. Secondly, Jane's 
level of fluency in French was somewhat higher than the other French NNS, and it is possible that her use of these expressions had been influenced by her recent stay in France.

We can conclude from the above frequencies that, in the case of the Australian English NNS, the lower frequency of the use of I think may well give the wrong impression to Australian English NS. As Australians, we would expect to hear I think relatively frequently in interaction, both to organise the discourse itself, but also to assure us that our interlocutor is not imposing their opinion on us, nor are they presenting it to us as fact. A low usage of this comment clause might contribute to the impression that our interlocutor is 'opinionated', as their opinions will seem to be expressed more forcefully. Accordingly, the 'overuse' of I find, which seems more personal and more binding in English, will contribute to this impression.

On the other hand, the seemingly overuse of the expression je crois by French NNS may give an impression of being 'wishy-washy' or not being committed to one's opinion to a French NS. The NNS' low (or non-) usage of je pense could be taken in two ways: either it would pass unnoticed if the NNS expressed their opinions anyway (this would simply be seen as a non-hedged expression of opinion, which would not be considered a problem for a French NS); or it could give a French NS the impression that their interlocutor's opinions had not been reflected on, since this process of reflection is part of the core meaning of je pense, and valued by French NS.

\section{Prosody of the comment clauses}

As stated, the prosody of the comment clauses was found to be central to the analysis of the comment clauses, both in the NS and the NNS data. The intonation contour and IU-position were the main factors involved in determining the exact functions of the comment clauses, although context was equally important at times.

The prosody of these comment clauses as organisational discourse markers typically involves acceleration and phonological reduction. Where the comment clause displays level intonation and no reduction, this usually indicates that the comment clause is being used to express an opinion. Doubt is usually indicated by a fall-rise intonation.

The prosodic features described above are applicable to both English and French, and therefore allowed for a comparable analysis of the NS and NNS data. The analysis of the NNS shows that proficiency levels are linked to intonation and prosody. Those NNS who had spent some time on exchange at university in France (Darren and Jane) had acquired native-like intonation in their L2, and the prosody of their organisational comment clauses was often reduced and accelerated, like that of a NS. Interestingly however, Darren's use of je trouve was usually unreduced, indicating an expression of opinion with this comment clause, rather than any organisational function. Karen's (few) comment clauses were all uttered with level intonation, without reduction or acceleration, thereby giving the impression of using these comment clauses to always express an opinion or a belief. This is unlikely to have had any adverse 
effect in her L2 however, as French native speakers are used to their interlocutor expressing an opinion.

The NNS of English displayed similar tendencies in regards to proficiency and native-like prosody. Suzanne, who was on exchange at an Australian university, showed more native-like intonation in her comment clauses (albeit only four). She displayed reduction and acceleration, as well as a clear expression of doubt with one utterance of $I$ think. Daniel and Marie however, tended to apply a level and full intonation to their instances of $I$ think, with Daniel often putting an extra emphasis on the subject pronoun. A direct transference from French, this could have the effect of making the French native speakers sound rather 'opinionated' in English and intent on imposing their opinions on their interlocutor.

\section{Conclusion}

The aim of this chapter was to illustrate the non-isomorphic nature of the four comment clauses I think, je pense, je crois and je trouve, both semantically and interactionally. It was proposed that these semantic and interactional nuances may not always be evident to non-native French and Australian English speakers in their second language, and to discuss what effect this might have in interaction when they use these expressions of subjectivity in their L2 with native speakers.

It was argued that the underlying inherent semantic content of each comment clause is distinct, and core meanings for the four comment clauses were proposed: it was argued that disclaiming knowledge of the upcoming proposition was integral to the meaning of $I$ think in Australian English, but that this need to distinguish fact from opinion is not part of the core meaning of any of the three French comment clauses. It was proposed that these core meanings are not necessarily evident to nonnative (or indeed native) speakers in interaction, and that transferring the expression from one's L1 can have different implications in the L2, possibly leaving one's native L1 interlocutor with a negative impression for example, the French speakers might appear 'arrogant' or 'opinionated', and the Australian English speakers 'wishy-washy' or without considered opinions.

We also set out to answer three questions, the first of which is as follows:

a) How does the frequency of the comment clauses in the (French and English) NNS discourse compare with the frequency in the NS discourse?

It was shown that $I$ think is overwhelming prevalent in NS discourse, and that on the contrary, the glosses for je crois and je trouve (I believe and I find) were extremely rare. The Australian English NNS all used I think to varying degrees, with two out of three showing similar patterning to the majority of the Australian English NS; the third speaker used very few tokens of I think. One NNS used I find much more often than the NS.

It was found that for the French NS, je pense was the most frequent expression of the three, and occurred three and a half times more often than je crois, followed by je trouve. Only one NNS followed the pattern 
established by the French NS; the other French NNS did not use je pense at all. One NNS used je crois very frequently, and overall two of the NNS used this comment clause over three times more often that the NS). The third NNS hardly used any of the French comment clauses.

We concluded from the above comparative frequencies that the less frequent use of $I$ think (and the more frequent use of I find) by French L2 speakers of English may well give the wrong impression to Australian English NS, i.e. that their interlocutor is 'opinionated'. On the other hand, the increased use of the expression je crois by Australian English L2 speakers of French may give the impression of being 'wishy-washy' or not committed enough to one's opinion to a French NS.

The following two questions will be addressed together:

b) Which functions do the comment clauses have in the native speaker discourse?

c) Which of these functions also occur in the non-native discourse?

It was found that interactionally all four comment clauses are multifunctional and have three main roles in discourse as follows: organisational (e.g. to mark a boundary in discourse), semantic (to express an opinion/level of certainty) and pragmatic (as a face saving device). The comment clauses may all perform more than one of the above functions at any one time, and were determined in each case by analysing the prosody, IU-position, and context of each comment clause.

These functions of the comment clauses were originally identified in NS discourse (for both languages), and then also found to occur in the NNS discourse, although it was found that some functions were more common in either the French or Australian English NS data.

The final question addressed was:

d) How do the frequencies of the functions of the comment clauses compare in NS and NNS discourse?

It was shown that the NNS of French used je pense and je crois as organisational discourse markers more often than the French NS (particularly to mark a boundary in discourse), and that the NNS considered je trouve to be predominantly a marker of speaker opinion. The NNS of English used $I$ think less often as an organisational discourse marker than the Australian English NS.

In addition, the NNS of French used je pense and je crois rather less often than the French NS to express an opinion, but used je trouve overwhelmingly for this purpose - much more often than the native speakers. Conversely, the NNS of English used I think to express an opinion significantly more often than the Australian English NS, who prefer to use this comment clause to organise discourse.

It is not clear to what extent NS are aware of the functions of these comment clauses in their L1, and for this reason, it is difficult to say whether the subtleties of the NNS use of these clauses will be noticed. It is possible that the NNS 'under-' or 'over-' use of a clause for a particular function may give the wrong impression to the NS, but no firm conclusions can be drawn on this point without further analysis (see below, however). 
One conclusion which can be drawn is the impression that the NNS prosody will give to the NS. While an Australian English NS who utters the French comment clauses with full and unreduced prosody will not usually encounter a problem (since French NS expect to hear their interlocutor regularly expressing their opinion), the French NS who consistently utters $I$ think as an unreduced comment clause, with equal (if not emphatic) stress on the subject pronoun, will unwittingly give the impression that they are 'opinionated' and intent on continually imposing their opinions on their interlocutor.

It was pointed out earlier that few interlanguage pragmatic studies to date have studied the acquisition of pragmatic markers (such as the comment clauses investigated here), and yet the importance of both pragmatic competence and the roles of such comment clauses in discourse is widely accepted. As Aijmer (2002) points out

Native speakers use discourse particles with great precision as signposts in the interaction, for example to make it easier for the hearer to understand how the different parts of the text are related. If a non-native speaker uses discourse particles incorrectly or not uses them at all this may lead to misunderstandings. A structural and functional description of discourse particles will therefore be useful for learners [...] (p. 3; my emphasis)

The fact that native Australian English NS use (and expect to hear) the comment clause $I$ think in discourse almost twice as often as French NS use the 'equivalent' comment clauses, no doubt contributes to the stereotypical impression that English speakers often have of French speakers, i.e. that they are "rude" and "arrogant" (Béal, 1990, p. 18), or at the very least imposing their opinions on their interlocutor. On the other hand, to a French NS, the prevalence of such comment clauses in Australian English interaction may well be misleading and contribute to the impression that Australian English speakers are "wishy-washy" (Béal, 1998, p. 6). Tendencies to 'under-' or 'over-' use these comment clauses transferred to one's L2 will ensure that these negative impressions of the Other persist.

Kerbrat-Orecchioni (2005, p. 42) quotes a survey mentioned in the French newspaper Libération (23rd January 2002) as stating that 19\% of the English consider the French "the most impolite nation on earth". It is not known how many people were surveyed, how "impoliteness" was defined, whether another nation was found to be more "impolite" overall than the French, or what the remaining 71\% of the English thought - all of which clearly brings the value of the findings (and indeed of such a survey) into question. Nevertheless this once again highlights and, more importantly, reinforces the long-standing fraught relationship between the French and English speaking nations. This relationship has developed for a wide range of historical and cultural reasons which cannot be entered into here; suffice it to say that it has been de rigueur for these nations to negatively stereotype and misunderstand one another for a long time. It is to be hoped that this study might go some small way towards reversing this trend. 


\section{Transcription Conventions}

(based on Du Bois et al.,1993; Jefferson, 1994)

\begin{tabular}{ll}
$\cdot$ & final intonation contour \\
$?$ & continuing intonation contour \\
$\dot{L}$ & appeal intonation contour \\
$\downarrow$ & very gently rising intonation contour \\
$\uparrow$ & falling pitch \\
-- & rising pitch \\
wou- & truncated intonation unit \\
{$[\quad$ truncated word } \\
$=$ & overlapping speech \\
LOUD & latching speech \\
${ }^{\circ}$ soft voice \\
$>$ fast $<$ & increased volume \\
$<$ slow $>$ & increased volume \\
$\wedge$ & decreased speed \\
$($ H) & primary accent \\
$($ Hx $)$ & inhalation \\
$()$. & exhalation \\
$(1.0)$ & break in rhythm (0.2 seconds or less) \\
$\ldots .$. & time intervals over 0.3 seconds \\
the::n & extraneous data / quotation omitted \\
$\{\quad\}$ & lengthened sound or syllable \\
& researcher's comments (to provide more context or \\
. & background information useful to the reader) \\
\hline
\end{tabular}




\section{References}

Aijmer, K. (2002). English discourse particles. Evidence from a corpus. Amsterdam: John Benjamins

Béal, C. (1990). 'It's all in the asking': A perspective on problems of cross-cultural communication between native speakers of French and native speakers of Australian English in the workplace. ARAL Series $S$, 7, 16-32.

Béal, C. (1992). Did you have a good week-end? Or why there is no such thing as a simple question in cross-cultural encounters. Australian Review of Applied Linguistics, 15 (1), 23-52.

Béal, C. (1998). Keeping the peace: A cross-cultural comparison of questions and requests in Australian English and French: In P. Trudgill \& J. Cheshire (Eds.), The sociolinguistics reader: Vol. 1, Multilingualism and variation (pp. 5-43). London: Arnold.

Béal, C. (2010). Les interactions quotidiennes en français et en anglais: de l'approche comparative à l'analyse des situations interculturelles. Frankfurt am Main: Peter Lang.

Biber, D. et al. (1999), Longman grammar of spoken and written English, Longman, Harlow.

Brinton, L. (2008). The Comment Clause in English: Syntactic origins and pragmatic developments. Cambridge: Cambridge University Press.

Chafe, W. (1993). Prosodic and functional units of language. In J. A. Edwards \& M. D. Lampert (Eds.), Talking data: Transcription and coding in research (pp. 33-43). London: Lawrence Erlbaum Associates.

Coates, J. (1997). Women's friendships, women's talk. In R. Wodak (ed.), Gender and discourse (pp. 245-262). London: Sage.

Coates, J. (1998). Gossip revisited: language in all-female groups. In J. Coates (ed.), Language and gender: a reader (pp. 226-253). Oxford: Blackwell.

Doro-Mégy, F. (2008). Étude croisée de think, believe, croire et penser. Paris: Éditions Ophrys.

Du Bois, J. W., Schuetze-Coburn, S., Cumming, S. \& Paolino, D. (1993). Outline of discourse transcription. In J. A. Edwards \& M. D. Lampert (Eds.), Talking data: Transcription and coding in research (pp. 45-89). London: Lawrence Erlbaum Associates.

Gumperz, J. J. (1982). Discourse strategies. Cambridge: Cambridge University Press.

Gumperz, J. J. (1992). Contextualization and understanding. In A. Duranti \& C. Goodwin (Eds.), Rethinking context: Language as interactive phenomenon (pp. 229-252). Cambridge: Cambridge University Press.

Halliday, M. A. K. (1994). An introduction to functional grammar, London: Edward Arnold.

Halliday, M. A. K. (2004). An introduction to functional grammar. London: Edward Arnold. $3^{\text {rd }}$ ed.

Jefferson, G. (1994). Conversation Analysis transcription. ARAL Series $S$ $11,185-191$.

Kaltenböck, G. (2008). Prosody and function of English comment clauses. Folia Linguistica, 42 (1), 83-134. 
Kaltenböck, G. (2009a). Is that a filler? On complementizer use in spoken object clauses. Vienna English working papers, 18 (1), 28-63.

Kaltenböck, G. (2009b). Initial I think: main or comment clause? Discourse and interaction, 2 (1), 49-70.

Kärkkäinen, E. (2003). Epistemic stance in English conversation. A description of its interactional functions, with a focus on I think. Amsterdam: John Benjamins.

Kärkkäinen, E. (2007). The role of I guess in conversational stancetaking. In R. Englebretson (Ed.), Stancetaking in discourse (pp.183-220). Amsterdam: John Benjamins.

Kasper, G. \& Rose, K. R. (2002) Pragmatic development in a second language. Massachusetts: Blackwell Publishing.

Kerbrat-Orecchioni, C. (1990). Les interactions verbales (Vols. I-III), Paris: Armand Colin.

Levinson, S. C. (1983). Pragmatics. Cambridge: Cambridge University Press.

Lipovsky, C. (2000). Impression management in cross-cultural job interviews. Paper presented at ALAA, University of Melbourne, July 2000.

Mullan, K. (2007). Cultural differences in the expression of opinion: a comparison of interactional strategies in French and Australian English discourse, Doctoral dissertation, Department of Linguistics, La Trobe University, Australia.

Mullan, K. (2010). Expressing opinions in French and Australian English discourse: A semantic and interactional analysis. Amsterdam: John Benjamins.

Müller, S. (2005). Discourse markers in native and non-native English discourse. Amsterdam: John Benjamins.

Pomerantz, A. (1984). Agreeing and disagreeing with assessments: Some features of preferred / dispreferred turn shapes. In J. M. Atkinson \& J. Heritage (Eds.), Structures of social action: Studies in conversation analysis (pp.57-101). Cambridge: Cambridge University Press.

Redeker, G. (1991). Linguistic markers of discourse structure. Linguistics, 29, 1139-1172.

Schegloff, E. A. (1981). Discourse as an interactional achievement: Some uses of 'uh huh' and other things that come between sentences. In D. Tannen (Ed.), Georgetown University Round Table on Languages and Linguistics 1981 (pp. 71-93). Washigton: Georgetown University Press.

Schiffrin, D. (1990). The management of a co-operative self during argument: The role of opinions and stories. In A. D. Grimshaw (Ed.), Conflict talk: Sociolinguistic investigations of arguments in conversations (pp. 241-259). Cambridge: Cambridge University Press, Cambridge.

Schourup, L. (1985). Common discourse particles in English conversation. New York: Garland Publishing Inc.

Stenström, A-B. (1995). Some remarks on comment clauses. In B. Aarts, C. F. Meyer (Eds.), The verb in contemporary English: Theory and description (pp. 290-301). Cambridge: Cambridge University Press. 
Tateyama, Y., Kasper, G., Mui, L. P., Tay, H-M. \& Thananart, O. O. (1997). Explicit and implicit teaching of pragmatic routines. In L. F. Bouton (Ed.), Pragmatics and language learning Vol. 8 (pp. 163-178). Urbana-Champaign, IL.: University of Illinois.

Thomas, J. (1983). Cross-cultural pragmatic failure. Applied Linguistics, 4 (2), 91-112.

Wardaugh, R. (1985). How conversation works. Oxford: Basil Blackwell. Wierzbicka, A. (1986a). Human emotions: Universal or culture-specific? American Anthropologist 88, 584-594.

Wierzbicka, A. (1986b). Introduction. Journal of Pragmatics 10, 519534.

Wierzbicka, A. (2006). English: Meaning and culture. Oxford: Oxford University Press.

Wise, J. (1999). The gift of the gab and how to get it. Sydney: Harper Collins Publishers Australia. 